\title{
ANÁLISE RELACIONAL DE MULHERES EM SITUAÇÃO DE VIOLÊNCIA CONJUGAL
}

\author{
RELATIONAL ANALYSIS OF WOMEN UNDERGOING INTIMATE PARTNER VIOLENCE
}

\author{
Ana Paula Tomio Greca ${ }^{1}$ \\ Gilberto Gnoato ${ }^{2}$
}

\begin{abstract}
${ }^{1}$ Graduada em Psicologia pela Universidade Federal do Paraná (2001-2006) , Especialização em Formação Pedagógica do Professor Universitário pela Pontifícia Universidade Católica do Paraná (2011), Especialização em Sexualidade Humana - Educação e Terapia pela Universidade Positivo (2018-2019). Psicóloga da Fundação de Ação Social desde 2011 e Coordenadora do Centro de Referência de Assistência Social na Prefeitura Municipal de Curitiba desde 2014. aptgrecapsico@ hotmail.com
\end{abstract}

${ }^{2}$ Graduado em Psicologia (1981). Especialista em Antropologia (1984), em Psicologia Clínica (2002) e Psicologia Social (2004) pela UFPR. Mestre em Psicologia da Infância e da Adolescência pela Universidade Federal do Paraná (2004). Doutor pela Universidade Federal Tecnológica do Paraná (2017). Coordenou - Curso de Psicologia da Faculdade Dom Bosco de Curitiba e lecionou também as disciplinas de Antropologia Social, Cultura e Sociedade Brasileira. Atuou como professor de Psicologia Social no Centro Universitário Positivo. Durante 20 anos foi professor e supervisor clínico na Universidade Tuiuti do Paraná. É comentarista da rádio Transamérica Light FM e psicoterapeuta de Orientação Psicanalítica há 20 anos. Consultor da revista Psicologia em Estudo do Departamento de Psicologia da Universidade Estadual de Maringá-Pr. Parecerista do Conselho Internacional de Estudos Contemporâneos (CONSINTER) da Editora Juruá. Professor convidado da Pós-Graduação em Sexualidade Humana da Universidade Positivo. ggnoato@onda. com.br
GRECA, A. P. T.; GNOATO, G. Análise relacional de mulheres em situação de violência conjugal. Akrópolis, Umuarama, v. 28, n. 2, p. 175-190, jul./dez. 2020.

\section{DOI: 10.25110/akropolis.v28i2.7660}

Resumo: Esta pesquisa teve como proposta destacar as contingências que levam a mulher a permanecer por longos períodos de tempo em relacionamentos violentos. O estudo caracterizou-se como pesquisa aplicada e uma vasta revisão bibliográfica foi realizada. A dinâmica da violência foi analisada sob a perspectiva relacional de gênero e, por meio da caracterização histórica do feminismo, a compreensão que concebe a violência como unilateral foi problematizada. Compreende-se que a violência não pode ser vista como uma ação individual, desarticulada do contexto macrossocial. Os sujeitos são dados na fusão histórica cultural do machismo, da sexualidade e do amor e comportam-se a partir destes dispositivos discursivos que perduram na história do ocidente e regulam as práticas sociais. $O$ que rege as relações entre os sujeitos são os procedimentos de poder que condicionam a realizar o que diz o discurso. Portanto, as relações de poder são estabelecidas por meio de discursos e conclui-se que um grande contingente das correlações de forças encontram-se no campo das relações entre homens e mulheres.

PalaVRas-Chave: Violência; Mulher; Perspectiva relacional de género; Dispositivos discursos.

Abstract: This study aimed at highlighting the contingencies that lead women to stay in violent relationships for long periods of time. The study was characterized as applied research and a large literature review was performed. The dynamics of violence were analyzed from a relational perspective of gender and, through the historical characterization of feminism, the understanding that conceives violence as unilateral was problematized. It is understood that violence cannot be seen as an individual action, disjointed from the macro-social context. The subjects are given in the historical cultural fusion of machismo, sexuality and love and behave from these discursive devices that perdure in the western history and regulate social practices. The relations between the subjects are ruled by the procedures of power that condition them to accomplish what is said by the discourse. Therefore, power relations are established through discourse and thus it can be concluded that a great contingent of correlations of force can be found in the field of relations between men and women.

KEYWORDS: Intimate partner violence; Relational perspective; Discursive devices. 


\section{INTRODUÇÃO}

\subsection{Delimitação do Problema}

A violência contra a mulher tem sido um tema debatido no mundo todo, devido a sua magnitude, seus custos econômicos e sociais. A Organização das Nações Unidas (ONU) em seu informe da Assembleia Geral, no ano de 2006, já apontava o custo intangível da dor e do sofrimento infligido às mulheres em situação de violência.

Segundo o Atlas da Violência (2018) elaborado pelo Instituto de Pesquisa Econômica Aplicada (IPEA) e pelo Fórum Brasileiro de Segurança Pública (FBSP) 4.645 mulheres foram assassinadas no país no ano de 2016, o que reflete uma taxa de 4,5 homicídios para cada 100 mil brasileiras. Quando considerada a década, entre os anos de 2006 e 2016, houve um aumento de $15,3 \%$ no número de assassinatos de mulheres. Os registros do Mapa da Violência (2015) apresentam um aumento de $252 \%$ no número de homicídios de mulheres no Brasil entre os anos de 1980 e 2013. Só durante o ano de 2013 os foram 13 homicídios femininos por dia. São dados alarmantes ao se pensar que estes índices referem-se, exclusivamente, a agressões letais e que ocorrências de violências física e psicológica sem vítima fatal não estão contabilizadas. Torna-se mais estarrecedor ainda ao se constatar que estas mulheres antes de sofrerem homicídio, vivenciaram, na maioria das vezes, uma série de outras violências (patrimonial, física, psicológica).

De acordo com o Atlas da Violência 2018, no $11^{\circ}$ Anuário de Segurança Pública constam 49.497 registros policiais de casos de estupros no ano de 2016, enquanto o Sistema de Informações de Agravos (SINAN) do Ministério da Saúde revela 22.918 notificações de atendimentos a este tipo de violência. Ao levar em conta a subnotificação, considerando uma taxa similar a norte americana que gira em torno de $85 \%$, a prevalência no Brasil seria entre 300 e 500 mil casos de estupros ao ano.

Recentemente, no Brasil, o Instituto DataSenado em conjunto com o Observatório da Mulher contra a Violência (2017) realizou um levantamento com mulheres de todas as unidades federativas do país sobre a violência doméstica e intrafamiliar contra a mulher. A pesquisa é realizada de dois em dois anos e esta última retratou um aumento alarmante dos índices. Desde 2005 o percentual de violência contra a mulher se mantinha em torno de $15 \%$ a $19 \%$, mas no ano de 2017 passou a $29 \%$, além do aumento de $15 \%$ das que afirmaram conhecer alguma mulher que já havia sofrido violência doméstica ou familiar. Os namorados, companheiros e atuais maridos foram apontados como os autores da agressão por $41 \%$ das participantes e outras 33\% citaram pessoas de relacionamentos passados. Portanto, um total de $74 \%$ dos agressores tem ou tiveram relacionamento afetivo com a vítima.

Este contexto traz desafios substanciais para aqueles que trabalham com oatendimentoàs mulheres em situação de violência. Profissionais dos diferentes serviços especializados na área de violência contra a mulher, como delegacias, centros de referências, instituições de acolhimento e serviços de saúde enfrentam uma atuação limitada, pontual e com resultados exíguos. Não há efetividade nas intervenções no sentido de romper com a relação violenta. No momento do atendimento uma quantidade considerável de mulheres recua, principalmente quando se impõe a obrigatoriedade do boletim de ocorrência. Dessa forma, as concepções dos serviços conflitam com o propósito que estas mulheres possuem ao buscar assistência.

Grande parte dessas questões se repete desde a criação do primeiro serviço de atendimento à violência contra a mulher no país - o SOS Mulher, lançado na cidade de São Paulo, em 10 de outubro de 1980 (SILVEIRA, 2006 , p. 52). O SOS Mulher foi a primeira instituição a ofertar atendimento às mulheres que vivenciavam situação de violência conjugal. O serviço prestava informações sobre direitos e orientação jurídica gratuita, além da realização de manifestações públicas de denúncia e reivindicações (GREGORI, 1993b). O trabalho era desenvolvido por voluntárias, feministas militantes que procuravam dar visibilidade à violência que ainda estava extremamente restrita ao espaço doméstico. "Imbuídas da concepção marxista", tinham como proposta um trabalho de conscientização da mulher contra a opressão masculina (GNOATO, 2014, p. 8). As idealizadoras do projeto acreditavam que sob a perspectiva de uma nova consciência, seria possível a construção de um novo ser social e político. "A consciência histórica sobre a agressão", sobre sua própria história de vida, "somada à consciência histórica sobre 
o machismo" (GNOATO, 2014, p. 8) seria a trajetória a se percorrer para a emancipação. Contudo, a entidade foi incapaz de alcançar os objetivos a que se dera. De acordo com Gregori (1993b, p. 79) 90\% das mulheres que procuraram o SOS não retornaram para dar continuidade ao atendimento, elas "não sentiram essa visita como experiência diferenciada das demais buscas de ajuda". Enquanto as plantonistas do SOS idealizavam uma mudança de consciência e de atitude das mulheres atendidas em relação ao parceiro, grande parte das que inicialmente haviam denunciado seus agressores, retirava as queixas registradas (SANTOS, IZUMINO, 2005). Portanto, na experiência militante do SOS, cuja característica principal era o discurso da denúncia e a instrumentalização da mulher para romper com as amarras da opressão enquanto sujeito autônomo e independente do homem, não havia espaço para considerar o fato de que as vítimas não pretendiam criminalizar seus parceiros e nem desfazer 0 casamento. As atendentes voluntárias, guiadas por um pensamento ideológico, não levaram em consideração as relações entre os pares, ignoraram a "existência de um sujeito situado na sua relação particular e intersubjetiva com o outro"(GNOATO, 2014, p. 9).

O movimento do SOS, sob a perspectiva do patriarcado, concebia a violência contra a mulher como resultado da opressão masculina e supunha a existência de "uma identidade feminina" (GROSSI, 1991, p. 4), enxergando a mulher como uma categoria única e universal. Grossi (1991, p. 4), numa concepção crítica, afirma que o conceito de opressão serve "para tornar as mulheres iguais", todas potencialmente vítimas de violência, prescrevendo a elas, por conseguinte, um destino inexorável. Para Silveira (2006), na visão vitimista não há espaço para ressignifcar as relações de poder uma vez que o gênero é o destino, pois desconsidera as diferenças entre as próprias mulheres, as crenças e o valores em que estão inseridas, como se houvesse uma essência feminina.

A análise relacional rejeita a concepção de homem e mulher como categorias portadoras de essências separadas, mas as compreende como dimensões complementares que se engendram na relação social entre os sexos. Portanto, trata-se de um entendimento dialético em que uma coisa só existe na relação com a outra, "relação é uma coisa que não pode ser ela mesma, se não houver outra. Relação é uma coisa que não pode existir sem que haja outra coisa para completá-la" (GNOATO, 2014, p. 10). Segundo Grossi (1991), "a violência é fruto de uma relação de complementariedade", desigual sem dúvida. Trata-se da compreensão do fenômeno da violência enquanto processo relacional, análogo ao poder. Gnoato (2017, p. 46), embasado no pensador francês Michel Foucault, afirma tratar-se da "microfísica da violência", relações de poder que se dão de todos para todos e que embora estruturem sistemas de desigualdade, não incidem necessariamente do homem sobre a mulher, mas que segundo Grossi (1991) fazem parte de um jogo relacional em que homens e mulheres desempenham papéis complementares em ações e falas cotidianas, em práticas discursivas culturais.

Afastando-se da visão descritiva utilizada pelo SOS Mulher e nos anos $80 \mathrm{em}$ geral quando se adotava uma compreensão jurídica, polarizada entre culpados e vítimas, este trabalho adotará uma perspectiva relacional de gênero para compreender as contingências que levam a mulher a permanecer por longos períodos de tempo em situação de risco com parceiros violentos. A abordagem relacional apresenta uma concepção analítica de gênero, a qual possui uma visão histórica e cultural da categoria. Dessa forma, para se analisar os processos que mantém a mulher em situação de violência, faz-se necessário incluir a dimensão particular das relações onde se encontram estes sujeitos, suas histórias de vida, suas subjetividades, escolhas afetivas e sexuais, além do aspecto macrossocial em que se situa o contexto cultural, histórico e social.

O foco da pesquisa refere-se a mulheres que possuem vínculo com o agressor, com os quais elas mantiveram ou mantêm um relacionamento. Abrange também outras formas violências além da física, pois "a violência imaterial, psicológica, discursiva também afeta os relacionamentos" (GNOATO, 2017, p. 46).

\subsection{Justificativa}

O fenômeno da violência contra mulher adquiriu uma trágica relevância diante do aumento alarmante das taxas de homicídios, assim como da significativa incidência de outras formas de violência. O Brasil é o $5^{\circ}$ país que mais mata mulheres segundo o Mapa da Violência homicídios contra mulheres (2015). No mesmo 
documento, o Estado do Paraná, no ano de 2013, apresentou uma taxa de homicídios em torno de 5,2 mulheres a cada 100 mil e a cidade de Curitiba registrou uma taxa de 6,2 mulheres assinadas. Ambos os índices acima da média nacional para o mesmo período que foi de 4,8 . $\mathrm{Na}$ década entre os anos de 2003 e 2013, o Paraná teve um aumento de $15,1 \%$ na taxa de homicídios e o país um acréscimo de $8,8 \%$. A Delegacia da Mulher da capital do Estado do Paraná registrou 27 ocorrências diárias no ano de 2011 (GNOATO, 2014).

Diante de números tão expressivos, a prática profissional da pesquisadora como psicóloga na política pública da Assistência Social, no Centro de Referência de Proteção Social Básica (CRAS), local em que, na grande maioria das vezes, são realizados os primeiros atendimentos de assistência à mulher em situação de violência, trouxe uma questão intrigante. O que leva um número significativo de mulheres que procuram os serviços a declinar dos atendimentos ou até mesmo a negar o suporte ofertado pelas diferentes políticas públicas que compõem a rede de proteção? Qual é o aspecto presente que os diversos serviços da rede não contemplam?

Isso posto, o presente estudo se justifica perante a necessidade de se obter uma maior clareza do processo que leva às mulheres a permanecer por longos períodos de tempo numa relação violenta, mesmo com assistência ou independência financeira. Questões como estas já eram presentes desde a década de 80 , no cotidiano do primeiro serviço de atendimentos às mulheres vítima de violência. Segundo Santos e Izumino (2005, p. 2), nos anos que se seguiram, o estudo da "frequente retirada da queixa por parte da vítima" adquiriu um "status privilegiado de investigação".

Outro ponto fundamental que determinou a escolha do tema foi que a maioria das pesquisas vem estudando mais os aspetos sociais do que as dimensões emocionais, psíquicas e afetivas, guiando de forma insuficiente as práticas profissionais. A lacuna existente refere-se a "dimensões particulares e microscópicas nos estudos de gênero" (GNOATO, 2014, p. 7), como a afetividade e o desejo, assim como a pouca importância atribuída ao discurso do amorpaixão. Grossi (1991, p. 14) ressalta que seria pertinente a psicologia estudar "os mecanismos inconscientes que mantém a mulher em uma relação de violência prolongada".

Para Gnoato (2014, p. 17) "não existe fenômeno de causa única em ciências sociais e humanas", portanto para um avanço da leitura do fenômeno da violência contra a mulher é imprescindível integrar o modo de pensar de várias disciplinas. A relação entre a Psicologia e a Antropologia, por exemplo, possibilita enxergar o masculino e o feminino como estrutura física significada culturalmente, ao ver da Antropologia, e constituída pelas representações na visão da psicologia (GNOATO, 2014, p. 7). Permite também caminhar em direção à uma decodificação das representações que incidem diretamente nas práticas profissionais, possibilitando uma ressignificação da atuação e uma qualificação da escuta profissional.

\subsection{Objetivos}

\subsubsection{Gerais}

Destacar as contingências que levam a mulher a permanecer por longos períodos de tempo em situação de risco em relacionamentos violentos.

\subsubsection{Específicos}

Caracterizar as incursões históricas do feminismo e dos estudos sobre violência contra a mulher.

Compreender a dinâmica da violência contra a mulher sob perspectiva relacional de gênero.

\subsection{Método}

\subsection{Caracterização da Pesquisa}

A pesquisa teve como característica a abordagem qualitativa, pois centrou-se na compreensão da dinâmica do fenômeno da violência contra a mulher e nas relações entre a subjetividade e o contexto histórico cultural. Com o objetivo de esclarecer questões encontradas no cotidiano de trabalho e gerar conhecimentos para aplicação prática, optou-se pela modalidade denominada Pesquisa Aplicada (BARROS e LEHFELD, 2000; GIL, 2002). A pesquisa constituiu-se na revisão bibliográfica com a análise teórica de material já publicado por meio eletrônico ou escrito, como livros, artigos científicos e teses. Segundo Fonseca (2002, p. 32) "a pesquisa bibliográfica é feita a partir do levantamento de referências teóricas já analisados [...] com o objetivo de recolher 
informações ou conhecimentos prévios sobre o problema a respeito do qual se procura a resposta".

\section{REVISÃO DE LITERATURA}

\subsection{Movimento Feminista}

A partir do final dos anos 70 , em meio às mudanças sociais e políticas no país, o movimento feminista adquire visibilidade (GNOATO, 2014). Desde então, acompanhando o processo de redemocratização, surgem os primeiros estudos sore violência contra mulher (SANTOS; IZUMINO, 2005). A temática foi utilizada como "bandeira de luta do movimento feminista" e, entre as inúmeras reivindicações dos anos 70/80, foi a questão melhor apropriada pelo Estado com a criação das Delegacias de Defesa da Mulher (GROSSI, 1991, p. 1). A primeira delegacia foi implantada, de forma pioneira no mundo, na cidade de São Paulo, em agosto de 1985 e, segundo Santos e Izumino (2005), constitui ainda hoje a principal política pública de enfrentamento à violência contra a mulher. Mas, desde 1980 já funcionava, no mesmo município, o "primeiro serviço de assistência social e psicológica a mulheres agredidas por seus parceiros - o SOS-Mulher" (GNOATO, 2017, p. 89).

A maior parte desses estudos, assim como o movimento feminista, procurava dar visibilidade à violência contra a mulher, tendo como foco de análise conhecer quais eram as denúncias, quem eram as mulheres que sofriam violência e qual era o perfil do agressor (SANTOS e IZUMINO, 2005). Segundo Gnoato (2017, p. 90) evidenciar a denúncia da agressão foi "historicamente necessário", pois pela primeira vez no Brasil a violência contra a mulher saia da esfera privada e tornava-se pública. Presume-se que por causa de tal visibilidade houve diversos trabalhos de pesquisas em delegacias e, em serviços voltados às mulheres em situação de violência.

O movimento feminista nos anos 60/70 buscava igualdade de direitos entre homens e mulheres, era o "feminismo das semelhanças", nominado sufragismo, e representava as mulheres como uma categoria singular, portadora de uma mesma essência (GNOATO, 2017, p. 107). Ests suposta universalidade e unidade do sujeito do feminismo dificultava o desenvolvimento de pesquisas na área, visto que a "mulher enquanto objeto ideal só existia em nível de ideologia" (CONCEIÇÃO, 2009, p. 740).

Em 1980 deu-se a segunda onda do feminismo quando "a mulher passa a ser tratada como uma categoria diferenciada dos homens", o âmago agora passa a ser a diferenciação, estabelecendo-se assim o feminismo da identidade (GNOATO, 2017, p. 108). Contudo, a noção de que existe uma definição singular do ser mulher torna-se equívoca e desloca o debate às diversas "dimensões que constituem as fronteiras humanas" (GNOATO, 2014, p. 2) como raça, classe, idade e crenças. Diante das diferenças o feminismo se pulveriza visando "objetivos políticos, materiais e culturais específicos" (CONCEIÇÃO, 2009, p. 749), dando origem a uma variedade de feminismos - "feminismo cultural, humanista, marxista, socialista, psicanalítico, radical, lésbico, negro, pós estruturalista, do terceiro mundo etc." (CONCEIÇÃO, 2009, p. 748), os quais não podem ser vistos como uma configuração única. Já nos anos 90, embora a maioria das pesquisas ainda tivessem como objeto de estudo as delegacias da mulher, não se limitavam a mapear as denúncias. De acordo Santos e Izumino (2005) os trabalhos passam a analisar a dinâmica da queixa, visto que a criminalização do agressor, na maior parte das vezes, não era almejada pelas mulheres em situação de violência, nem pelos agentes do Estado. Sob influência dos debates norte-americanos e franceses sobre a construção social do masculino e do feminino, os estudos feministas no Brasil passam a utilizar o conceito de gênero como "categoria de análise das relações entre homens e mulheres" (SANTOS; IZUMINO, 2005, p. 3). Dessa forma, a terceira onda do feminismo afasta-se da categoria mulher para caminhar em direção a categoria de gênero.

Além da influência teórica internacional e nacional sobre o uso e a definição de gênero, as pesquisas nos anos 90 também foram influenciadas pelo cenário jurídico e político externo e interno. O Brasil ratificou normas internacionais que reconheciam os direitos das mulheres como direitos humanos, trazendo tal paradigma as práticas e estudos feministas. Dessa forma, a preocupação com a ampliação dos direitos humanos das mulheres e o exercício da sua cidadania passam a ser enfatizadas (SANTOS, IZUMINO, 2005). 
O trabalho do Comitê para a Eliminação da Discriminação contra a Mulher, presente no informe das Nações Unidas (2006), afirma que a violência contra a mulher é uma grave violação dos direitos humanos, com efeitos devastadores a sua saúde e ao seu bem-estar. Entende-se Direitos Humanos como os princípios morais que:

consideram o outro merecedor de igual consideração e profundo respeito, dotado do direito de desenvolver as potencialidades humanas de forma livre, autônoma e plena. É a ética orientada pela afirmação da dignidade e pela prevenção ao sofrimento humano (PIOVESAN, 2012, p. 72).

O informe supracitado faz referência também a Declaração sobre Eliminação da Violência contra a Mulher de 1993 e aponta que tal violência é produto de "relações de poder historicamente desiguais entre homens e mulheres" (ONU, 2006, p. 18) e reconhece que "toda forma de violência contra a mulher se constitui numa forma de discriminação por motivos de gênero" (ONU, 2006, p. 17). No Programa de Ação resultante da Conferência de Direitos Humanos celebrada em Viena (1993) e referido também no documento da ONU (2006) faz-se um apelo à eliminação da violência por motivos de gênero.

Segundo Gnoato (2017, p. 108), nos anos 1990, as teorias pós-estruturalistas procuraram "descontruir a categoria mulher para a análise das diferenças de gênero". Butler (2013, p. 18) afirma que a concepção dominante do feminismo passou a ser questionada "a partir do interior do próprio discurso feminista" e o ser mulher "não é mais compreendido em termos estáveis e permanentes". Costa (1998, p. 132 apud GNOATO, 2014, p. 1) afirma que tais desconstruções geraram uma "categoria oca", a "mulher passou a ser aquilo que não pode existir".

Portanto, o presente estudo propõe um retorno a categoria mulher, mas com uma visão dialética do termo e não mais carregada de essencialismo. A dialética concebe o objeto de estudo em seu contexto histórico, cultural e social, pois compreende-o de forma indissociável dos elementos que o rodeiam, das mediações que o constitui (ALVES, 2010). Não pode ser compreendido de forma isolada, visto que está condicionado às relações existentes entre os elementos contrapostos e a sua totalidade histórico-social.

\subsection{Estudos Sobre a Violência Contra a Mulher}

A partir dos anos 1980 três abordagens embasaram os diferentes estudos na leitura do fenômeno social da violência contra a mulher. A teoria intitulada Dominação Masculina utilizava o conceito de violência contra a mulher como sinônimo de opressão (GROSSI, 1991). Segundo Santos e Izumino (2005, p. 3) essa referência tem origem no artigo de Marilena Chauí (1985) intitulado "Participando do debate sobre mulher e violência". A filósofa conceitua violência como o desrespeito ao "direito de alguém ser sujeito constituinte de sua própria história" (GREGORI, 1993a, p. 144). Nesta concepção, a subjetividade feminina é constituída heteronomamente, portanto destituída de autonomia. O ser feminino está subordinado à condição da maternidade, a de ser esposa, mãe, cuidadora, enfim de ser "para os outros" (GNOATO, 2017). Bourdieu (2014, p. 24) afirma que a diferença biológica entre os sexos é usada como "justificativa natural" para a distinção socialmente construída entre os papéis femininos e masculinos, para a construção hierarquicamente desigual da condição feminina. Portanto, transformam o arbitrário cultural em natural, as diferenças em desigualdades hierárquicas, por meio de uma ideologia que, segundo Santos e Izumino (2005, p. $3)$, concebem a "condição feminina como inferior à condição masculina". "São o que são pelos outros (que definiram seus atributos) e para os outros (aos quais os atributos são endereçados)" (CHAUÍ, 1985, p. 46 apud GREGORI, 1993a, p. 147). Trata-se da incorporação das estruturas históricas da ordem masculina por meio de "inconscientes esquemas de percepção" (BOURDIEU, 2014, p. 17). Não há consciência da relação social de dominação, pois a mulher possui instrumentos para pensar a si mesmo e a relação com o opressor que são, eles mesmos, produtos da própria dominação (BOURDIEU, 2014) e que anulam a possibilidade da mulher de estabelecer seus próprios interesses e destino, resultando na reprodução de sua sujeição. Tratase de uma "violência invisível a própria vítima, exercida por vias simbólicas da comunicação e do conhecimento" (BOURDIEU, 2014, p. 12).

Chauí considera que esses discursos 
são categorias de entendimento compartilhadas tanto por homens quantos por mulheres. A autora afirma que embora haja uma cumplicidade da mulher, ela "não se baseia numa escolha ou vontade" (SANTOS, IZUMINO, 2005, p. 4).

A referência teórica do Patriarcado foi inaugurada no país pela socióloga Helena Saffioti (SANTOS e IZUMINO, 2005), afirmando que a violência contra a mulher é uma repercussão da "violência estrutural" (GREGORI, 1993a, p. 143) perpetrada por um sistema de exploração, criticando concepções capitalistas e racistas. Para Saffioti a violência contra a mulher é expressão do patriarcado e não apenas uma subordinação ao modelo ideológico de dominação. Embora a socióloga compreenda a mulher como vítima da subordinação social, define como "sujeito dentro de uma relação desigual de poder com os homens" (SANTOS, IZUMINO, 2005, p. 4). Portanto, a socióloga descarta a ideia de Chauí, em que as mulheres são "cúmplices" involuntárias da produção e reprodução da violência. A mulher é vista como vítima do homem devido a um poder verticalizado, o qual é sustentado por um processo de socialização machista "que outorga ao homem o direito de dominar a mulher na condição de macho" e que a mulher é educada para submeter-se (GNOATO, 2017, p. 96).

Essas concepções teóricas
compreendem a dominação como uma situação partilhada entre as mulheres, como um destino imposto a elas pelo fato de serem mulheres, julga a todas de forma generalizada como vítimas, sem considerar suas configurações particulares ou seu contexto cultural, ignorando as diferenças entre as próprias mulheres, portanto concebeas como uma categoria singular. De acordo com Gregori (1993a, p. 145) essas visões apresentam "uma lógica dual e contrastante" entre vítimas e algozes, entre mulher e homem, entre heteronomia e autonomia, atribuindo a elas uma passividade, uma impossibilidade de agir e a eles uma ação agressiva, cristalizando um padrão de semelhança a todos os relacionamentos.

A terceira corrente que foi referência na busca da compreensão do fenômeno da violência contra a mulher é denominada relacional e busca relativizar a dicotomia dominação masculina e vitimização feminina. Segundo Santos e Izumino (2005), o estudo que inaugurou esta perspectiva foi o de Maria Filomena Gregori, intitulada Cenas e Queixas (1993). A autora considera que atribuir papéis específicos e fixos a homens e mulheres resulta numa "dualidade redutora" e que tais limites "são atualizados nas relações interpessoais, [...] entram em uma operação combinatória particular em cada relação de violência" (GREGORI, 1993a, p. 146), o que permite compreender o contexto em que a violência é produzida e o significado que assume. Gregori (1993b, p. 148) entende que a violência conjugal "pode ser uma forma de comunicação, ainda que perversa, entre os parceiros" e que "homens e mulheres conferem significados às suas práticas" (SANTOS, IZUMONO, 2005, p. 7) na interação com o outro. De acordo com Grossi (1991, p. 6), Gregori considera a violência "parte de um jogo relacional" em que, nas cenas de brigas, o homem e a mulher concorrem com imagens de masculinidade e feminilidade, compreendendo a violência de forma dialógica. O homem disputa com a mulher a posse da última palavra, pois esta outorga a ele um lugar histórico, o da razão, o da autoridade e "se ele não consegue fazê-la calar pela força do grito, do palavrão, a violência física é tomada como solução" (GNOATO, 2017, p. 166). Portanto, o processo inter-relacional que se encontra numa dimensão particular sustenta e é sustentado pelo contexto macrossocial, numa continua retroalimentação.

Apesar de Gregori coincidir com Chauí ao considerar que a mulher também contribui para a "reprodução dos papéis de gênero que alimentam a violência" (SANTOS, IZUMINO, 2005, p. 7), ela discorda que tal contribuição seja expressão da própria dominação masculina. Portanto, tem o entendimento que a mulher possui autonomia para de alguma forma alterar sua situação.

A queixa passou a ser o objeto de estudo, à medida que se identificou que as mulheres em situação de violência "não se posicionavam perante a separação do parceiro violento" (GNOATO, 2017, p. 98) e não almejavam denunciá-lo. Para Santos e Izumino (2005) há que se ter cautela para não considerar a queixa sempre um processo de vitimização, generalizando o seu significado como o fez Gregori. A queixa pode adquirir diferentes sentidos, pode ser interpretada, segundo Gnoato (2017, p. 99), "ora como um pedido, ora como uma solução, ora como ameaça, como proteção ou como comunicação". A pesquisa de Elaine Reis Brandão Brandão (1998, apud SANTOS e 
IZUMINO, 2005, p. 9) aponta que, sob o ponto de vista das mulheres, a suspensão da denúncia "é um instrumento de negociação com o parceiro, com vistas à manutenção, transformação ou dissolução da relação conjugal".

[...] em muitos casos, a queixa não é uma denúncia, mas um pedido de ajuda. Denunciar é tornar público. Tratase de um ato sociológico, enquanto que a queixa é um ato psicológico. $O$ enfoque na denúncia é um mecanismo de repressão contra a ação do agressor. $O$ enfoque na queixa é um mecanismo que pretende compreender a reação do agredido ou comunicar-se com ele por meio de outra linguagem ou ocupar outro lugar na relação (GNOATO, 2017, p. 99).

Izumino (1998, apud SANTOS e IZUMINO, 2005), sob uma perspectiva de gênero, compreende a violência como uma relação de poder. Para esta concepção, recorre à definição de gênero teorizada pela historiadora norteamericana Joan Scott, a qual afirma que "gênero é um campo primário no qual ou através do qual o poder é articulado", trata-se de "um elemento constitutivo das relações sociais, baseado em diferenças percebidas entre os sexos" (SANTOS, IZUMINO, 2005, p. 11). Segundo Butler (2004 apud DEBERT e GREGORI, 2008, p. 177) a produção e a regulação do masculino e do feminino se dão por variados modos e compõem "um conjunto de dispositivos que cria desigualdades de poder e, simultaneamente, está aberto a transformações", portanto adotado de forma nada fixa. Isso resulta em não mais considerar a violência contra a mulher como decorrente da dominação do homem sobre a mulher, em que o poder é concebido de forma estática e polarizada. A teoria relacional sobre a violência adotada por Santos e Izumino, a partir dos anos 90 , coincide com a concepção relacional de poder em Foucault que considera o poder não como fruto de um único elemento, mas sustentado por todos (GNOATO, 2017).

Como afirma Gnoato (2017, p. 99) "considerar o lugar da mulher na violência, não implica negar o ato criminoso do agressor, mas entender a lógica da agressão" a partir de perspectivas teóricas que tenham um mirante relacional.

\subsection{Noções de Violência}

A maioria dos estudos sobre violência contra a mulher classifica a violência em diferentes subtipos, como a violência física, sexual, psicológica, tortura etc. No entanto, a presente pesquisa considera que todas as formas de violência são violências psicológicas, pois, como afirma Gnoato (2017, p. 114):

O fato de existir uma materialidade (o corpo) não exclui a presença da imaterialidade, como o xingamento, a humilhação, a depreciação, a chantagem, as mentiras, as ameaças, a obliteração, o isolamento, o despotismo e uma legião de semânticas que levam ao pânico, ao terror, ao medo, à angústia, enfim a uma narrativa do sofrimento [...].

A violência inicia muito antes da tangibilidade do ato da agressão, mas naturalizada, é imperceptível e não reconhecida pela sociedade. A violência psicológica conduz à física e vice-versa, perpassando uma a outra, num processo de retroalimentação. De forma mútua, a linguagem violenta leva à ação violenta, num "círculo vicioso dialógico" (GNOATO, 2017, p. 115) e proveniente de uma cultura discursiva violenta.

Segundo Krug et al. (2002, p. 5), a Organização Mundial da Saúde no Relatório Mundial sobre violência e saúde em Genebra define que:

A violência configura-se como o uso da força física ou do poder real ou em ameaça, contra si próprio, contra outra pessoa, contra um grupo ou uma comunidade, que resulte ou tenha qualquer possibilidade de resultar em lesão, morte ou dano psicológico, deficiência de desenvolvimento ou privação [...]

Portanto a noção de violência é ampliada, abarcando práticas que advém das relações de poder como ameaças, intimidações, privações e inclui atos que não resultam necessariamente em lesão física ou morte, mas que da mesma forma infligem sofrimento e um "peso substancial em indivíduos, famílias, comunidades e sistemas de saúde em todo o mundo" (KRUG et al., 2002, p. 5). Dessa forma, a ampliação do conceito ao incluir violência imaterial, inscreve-a na linguagem, nomeando-a e descortinando-a 
para a sociedade com o objetivo de fazer ver, desnaturalizar, mudar a perspectiva da sociedade sobre a violência.

A violência não raras vezes é invisível, apesar de presente nas falas e ações cotidianas de casais e famílias carregadas de sentidos e significados imbricados na cultura, a qual "transborda a nossa mente e nossas ações" (GNOATO, 2017, p. 122). Portanto, vozes que são aparentemente particulares, são resultado de uma dimensão maior, de dispositivos discursivos culturais que "expressam e são expressões da vociferação da sociedade" (GNOATO, 2017, p. 125). Não se pode estudar a sociedade desvinculada do indivíduo, do que se está capilar na sociedade (microssocial) e vice-versa, o objetivo e o subjetivo estão interelacionados.

$\mathrm{O}$ que rege as relações entre os sujeitos são os procedimentos de poder, os quais não funcionam como mecanismo proibitivo, mas que por meio de dispositivos de dominação conduzem a fazer aquilo "que o discurso diz" (GNOATO, 2017, p. 49). Numa sociedade as relações de poder são estabelecidas por meio de discursos, o poder se infiltra em nossa concepção de mundo, conduz nossa vontade e pensamento como estratégia de regulação do corpo social. Desse modo, poder é algo que produz efeitos, que está em cada parte da organização social, se exerce nas relações afetivas, familiares, nas instituições, enfim, se "exerce de inúmeros pontos e em meio a relações desiguais e móveis" (FOUCAULT 2017, p. 102). Logo, nada encontra-se exterior a esse campo de correlações de forças, " (...) nem o discurso, nem o poder pertencem apenas a um lado. Eles são exercícios dialógicos que comunicam tanto homes quanto mulheres"(GNOATO, 2017, p. 104).

O poder produz regimes de verdade que são a estrutura de pensamento de um determinado momento histórico. Essas verdades são reverberadas e retroalimentadas pelos discursos, os quais não são entendidos apenas "como verbal, mas como um dispositivo" (GNOATO, 2017, p. 101). Michel Foucault (1982, p. 244 apud GNOATO, 2017, p. 47) concebe dispositivo como:

um conjunto decididamente heterogêneo que engloba discursos, instituições, organizações arquitetônicas, decisões regulamentares, leis, medidas administrativas, enunciados científicos, proposições filosóficas morais, filantrópicas. Em suma, o dito e o não dito são os elementos do dispositivo. O dispositivo é a rede que se pode estabelecer entre estes elementos. (FOUCAULT, 1982, p. 244).

Portanto, dispositivo é a rede constituída por todos esses elementos que são transmitidos por meio de imagens, ações, campos verbais, filmes, letras de músicas e instituições como escola, igreja etc. O sujeito e sua subjetividade são desenhados historicamente por estes dispositivos culturais que perduram na história do ocidente e regulam as práticas sociais. Tudo é atravessado pelo poder, pelas linhas de força que ao atuar, operam subjetividade.

"A violência discursiva, como um segmento do dispositivo cultural", também é produzida nestas condições históricas e materiais, "pois o discurso é uma prática orientada" (GNOATO, 2017, p. 113). As agressões físicas e simbólicas são ecos deste discurso instituído nos costumes, nos valores e nas representações sociais e que orienta condutas. O discurso da violência abrange a todas as classes sociais, faixas etárias, religiões e gêneros.

O discurso é o conjunto de proposições que detém a qualidade de verdade, "é a reverberação de uma verdade" (FOUCAULT, 2012, p. 6 apud GNOATO, 2018). A verdade é desenhada historicamente e muda de acordo com o tempo para "atender interesses de um determinado período" (SILVA, MACHADO JUNIOR, 2014, p. 7), impelindo o que pode ou não ser dito. A produção do discurso está envolta de poder, o qual estabelece uma série de procedimentos que determinam uma forma de saber. O poder é intrínseco às relações sociais e está capilarizado entre os sujeitos da sociedade. O poder não opera apenas na esfera da vida privada e tampouco só nas posições exercidas por homens e mulheres, pois o gênero é apenas um dos diversos preceitos de regulação de poder (FOUCAULT apud DEBERT; GREGORI, 2008, p. 177).

A violência entre casais expõe que tanto homens quanto mulheres estão submetidos a este arcabouço discursivo cultural que os constitui na historicidade da linguagem e que institui hierarquias por meio de estratégias que cristalizam crenças acerca da autoridade 
masculina e que mantém a mulher numa posição social fragilizada. Por isso Bourdieu (2014) afirmava que a cultura não é uma produção igualitária e nem livre. "No caso das sociedades modernas, as significações masculinas ocupam este lugar privilegiado" (GNOATO, 2017, p. 122).

A violência é dada neste e por este contexto, portanto se faz necessário refletir sobre o lugar do discurso no campo da violência e analisar a comunicação entre homens e mulheres, pois tanto comunicação quanto linguagem são dadas na cultura.

Essa memória discursivo-cultural molda e constitui nossas consciências e ações, levando-nos a perpetrar um universo desproporcional em que homens e mulheres se comunicam também pela agressão física e imaterial (GNOATO, 2017, p. 101).

\subsection{Fundamentação Teórica e Discussão}

$\mathrm{O}$ que leva um contingente de mulheres a permanecer por longos anos em relações violentas? Muitas sequer denunciam seus agressores e várias acabam sendo assassinadas. De acordo com o Mapa da Violência 2015, a maioria das agressões contra as mulheres foi perpetrada por seus parceiros ou ex-parceiros amorosos e cerca de $50 \%$ retornou a agredi-las. Este é um contexto relatado com frequência nas mídias, por exemplo, a RPC em 02 de agosto deste ano anunciou que no Estado do Paraná quatro mulheres foram vítimas de feminicídio em menos de um mês. O estudo de Gnoato (2017) também relata dois casos, como os ocorridos no ano de 2015 da fisiculturista R. M., que nunca deu queixa do parceiro, e da dentista de classe média M. S. "Quando indagadas pelos motivos que levaram a não denunciarem seus agressores, a resposta romântica-amorosa aparece na ponta da língua" "porque eu o amava"(GNOATO, 2017, p. 99).

Essas mulheres imersas num ideal amoroso a ser alcançado, que as destitui de racionalidade, num ato de defesa, constroem justificativas para a violência psicológica e física dos parceiros, culpando a bebida, a droga, os problemas no trabalho etc. Segundo Gregori (1993b) as mulheres em situação de violência que procuravam o SOS Mulher da cidade São Paulo, na década de 80, enxergavam a causa da violência como algo alheio à relação, atribuíamIhe outro sentido, o de um infortúnio: "fatalidade de ter casado com um homem bom, mas que bebe" (GREGORI, 1993, p. 141). Essa ideia de amor é uma dimensão supra individual que as governa, como afirma (PRIORE, 2006, p. 225): "Ama-se então, um conjunto de ideias sobre o amor (...) Ama-se o amor e não propriamente a pessoa".

Segundo Rougemont (1988) o ocidente ao incorporar o discurso do amor-paixão, originário do séc. XII e consolidado na gênese do indivíduo no séc XVIII, impõe um ideal de relacionamento que gera quase que uma total dependência do outro, pois a felicidade e a satisfação só ocorrem num contexto onde o casal se funde. Portanto, essas mulheres tomadas pelo dispositivo discursivo-cultural, submetidas à obrigação de um verdadeiro amor, apresentam dificuldade em distinguir o real do imaginário, vinculam-se muito mais a uma imagem idealizada do parceiro do que ao sujeito real (GNOATO, 2017, p. 106). Dessa forma, a violência se dá na intersecção da realidade cultural com a subjetividade da realidade psíquica. O amor-paixão impõem-se como um destino e se torna uma fonte de insatisfação e medo, pois "produz uma obrigação de desejar o outro e ser desejado por ele como uma simbiose" (GNOATO, 2017, p. 102).

Algumas mulheres têm a possibilidade de romper com o agressor, mas acabam retornando ao relacionamento violento ou, numa repetição sintomática, iniciam novos relacionamentos com os mesmos enfrentamentos do anterior. A escolha de um parceiro agressor pode ser resultado de uma repetição inconsciente de modelos afetivos da família de origem. Segundo, Freud (1970, p. 188 apud GNOATO, 2017, p. 101) as escolhas amorosas estão condicionadas ao "lugar que o sujeito ocupou na condição de filho(a)". Portanto, a qualidade das relações amorosos será decorrente das particularidades das relações entre pais e filhos. Se a posição da dor foi a maneira pela qual essa criança conseguiu reconhecimento e amor de seus pais, existe a tendência de se tornar um adulto (a) que entende que há a necessita de se sacrificar para ser amado (a). Tais relações familiares não estão desconexas do macrossocial, fazse importante destacar que há uma dimensão cultural da afetividade, pois "a família fala com os filhos por meio de uma linguagem que se dá na cultura" (GNOATO, 2017, p. 102).

Uma longa construção cultural dada na 
literatura, no teatro, nas músicas, no cinema, nas diferentes linguagens que circularam e circulam até o momento por todos os lugares, nos constitui ainda hoje como sujeitos apaixonados. Desde a Idade Média até os dias de hoje tragédias decorrem em nome deste amor, apaixonados que são assombrados pela perda do objeto amado ou pela possibilidade de uma traição.

O amor romântico estabeleceu-se com o romantismo, movimento da literatura que ocorreu por volta do séc. XVIII e, em negação a lógica lluminista, preconizava a irracionalidade e as escolhas da interioridade do indivíduo (ROUGEMONT, 1988). A idolatria ao amor perpetuado até os dias de hoje, encarcera os sujeitos num discurso de dependência do outro, impulsionando o receio da perda e fomentando o ciúme. Segundo Gnoato (2017, p. 137) na linguagem dos casais apaixonados "o ciúme é entendido como um sinal de zelo". Portanto, não se trata da dominação do homem sobre a mulher como considerada pela concepção da Dominação Patriarcal (SANTOS, IZUMINO, 2005) e sim de uma perspectiva que compreende que o ciúme não é uma prerrogativa masculina, pois tanto homens quanto mulheres vivem à sombra desta dependência. Esse dispositivo amoroso transcende o sujeito e avassala a todos.

Num contexto em que se prega a dependência do outro, os sujeitos assumem uma existência alicerçada no companheiro(a) para a completude de sua identidade. Todas as demais dimensões da vida, como a família, as amizades, o profissional, se anulam frente à ausência do outro. Segundo Fanini, Gnoato e Santos (2017, p. 146) "essa dependência é cultural e de difícil neutralização". Na conjugação do amor com o sexo (amor erótico), o ciúme torna-se uma obsessão diante da possibilidade de traição.

De acordo com Correa (1981 apud GNOATO 2017, p. 135) os crimes praticados por homens em defesa da honra tinham respaldo legal no Código Penal Brasileiro anterior a 1940. O argumento jurídico sustentava que o assassinato era uma reação masculina instintiva decorrente de uma paixão arrebatadora (PRIORE, 2006, p. 196). Compreende-se que tal entendimento jurídico e crime são reflexos de um dispositivo discursivo cultural do machismo que imbrica discursos do amor-paixão e da violência. Embora o Brasil tenha sancionado, em agosto de 2006, a imprescindível lei Maria da
Penha que tem a importante função de punir o agressor, esta não encarcera os dispositivos que reverberam o ideal de masculinidade associado à virilidade.

A violência não pode ser vista como uma ação individual, desarticulada do contexto macrossocial.

a construção discursivo-cultural da identidade masculina o apresenta como violento. Isso o leva a agir de modo violento e cremos que a cultura molda os homens e os instrumentaliza para a ação [...] temos um imaginário visual e discursivo que tem por milhares de anos, fomentado o homem guerreiro, invasor, portador de armas; soldado, caçador, a mulher surge como "meiga", "negociadora", "submissa", não afeita ao confronto. Esses discursos de longa duração moldam em parte, ações violentas que se estendem até a contemporaneidade. (GNOATO, 2017, p. 67).

O alicerce do machismo estaria nas definições de feminilidade e masculinidade que, segundo Bourdieu (2014, p. 54), impõe ao homem a obrigatoriedade de ser viril e a mulher a necessidade de ser bela, e sedutora. O machismo é reforçado nas falas do cotidiano, ao que Bakhtin (2014) segundo Gnoato (2017, p. 68) chama de "ideologia do cotidiano", valores, conceitos, preconceitos e julgamentos que são reproduzidos inclusive por mulheres, por conseguintes "todos em maior ou menor grau de conscientização aderem ao dispositivo". "Tratase de uma armadilha discursiva-cultural" em que expressões como "palavra de homem", "espere só seu pai chegar", valorizam o lugar do homem em detrimento ao da mulher (FANINI, GNOATO e SANTOS, 2017, p. 137 e p. 139 ).

O machismo perpetua uma assimetria em que a mulher é vista sempre numa posição inferiorizada. Portanto, a identidade feminina é concebida a partir do homem, numa dialogia hierarquizada, visto que um dos polos se torna negativo frente ao outro. Segundo Bourdieu (2014, p. 53):

A visão androcêntrica é assim continuamente legitimada pelas próprias práticas que ela determina: pelo fato de suas disposições resultarem da incorporação do preconceito 
desfavorável contra o feminino, instituído na ordem das coisas, as mulheres não podem senão confirmar seguidamente tal preconceito [...] Ela está em curso, quotidianamente, em inúmeras trocas entre os sexos.

A psicóloga Castañeda (2006) entende que para todo papel machista há uma correlata atitude feminina, que trata-se de uma dinâmica de complementariedade, portanto o machismo não é fruto do indivíduo mas uma forma de relação. "O inimigo a ser vencido não é a masculinidade, mas uma certa definição de masculinidade e, portanto, de feminilidade, que é a base do machismo" (CASTAÑEDA, 2006, p. 24). Dessa forma, num horizonte cultural mais amplo, convergimos com Castañeda (2006, p. 19): “Não são indivíduos machistas que constroem uma sociedade machista, é a sociedade machista que cria indivíduos machistas".

O encargos para se lograr um ideal de masculinidade numa sociedade competitiva e violenta, tornam os homens também vítimas da violência do poder simbólico, o qual estabelece um lugar a ser preenchido, uma espécie de confinamento simbólico. Segundo Bourdieu (2014, p. 79) "a virilidade, como se vê, é uma noção eminentemente relacional, construída diante dos outros homens, para os outros homens e contra a feminilidade (...)". Por conseguinte, trata-se de uma cilada que submete o homem à obrigação de provar em toda e qualquer circunstância sua virilidade. Se às mulheres pesam as exigências do dispositivo da sexualidade como a beleza e a jovialidade que completam um ideal feminino, além das restrições que as cercam, também não são aprazíveis as responsabilidades que recaem sobre os homens. A violência masculina está relacionada de modo direto com a virilidade.

Os sujeitos são dados na fusão histórica cultural da virilidade, da sexualidade e do amor e comportam-se a partir desses dispositivos que apresentam um aspecto interdependente.

Assim se percebe que essa construção prática, longe de ser um ato intelectual consciente, livre, deliberado de um "sujeito" isolado, é, ela própria, resultante de um poder, inscrito duradouramente no corpo dos dominados sob forma de esquemas de percepção e de disposições (a admirar, respeitar, amar etc.) que o tornam sensível a certas manifestações simbólicas do poder (BOURDIEU, 2014, p. 63).

\section{CONSIDERAÇOES FINAIS}

Há uma cultura de longa duração que constitui homens e mulheres e para se modificar as relações de violência há que se alterar esta macroestrutura. Os discursos presentes nas letras de música, nos enredos de filmes, nas leis, nos enunciados morais, na ciência, enfim, presentes nesta rede de significantes que formam o dispositivo, encarceram os sujeitos numa realidade cultural que gera condutas sociais. Portanto, não num ato de consciência ou voluntário, homens e mulheres incorporam esquemas de percepção, de avaliação e de ação, como princípios naturais de organização do mundo social, pois estão inscritos na ordem das coisas e dispensam a necessidade de se afirmar como tal. Essa dominação simbólica impõe ao sujeito uma ação subordinada, é algo que transcende a vontade consciente do sujeito, portanto libertar-se de tal realidade é bastante complexo. Não se pode negar a epígrafe das estruturas sociais na subjetividade do sujeito e nem pensar a violência desarticulada do sentido social. A partir desta concepção a violência não é vista como um produto do indivíduo, mas resultado de valores violentos veiculados no e pelo discurso.

O ideal de masculinidade imposto pelo dispositivo machista faz com que, numa "escolha" condicionada, mulheres desejem homens viris e que homens idealizem mulheres belas, jovens e passivas. Dessa forma, seu poder está em justapor desejos complementares. O machismo encontra-se na linguagem de homens e mulheres que reproduzem crenças acerca da virilidade e do lugar de autoridade do homem e da posição fragilizada da mulher como um ser emotivo e sensível perante este homem. As brigas entre os casais expressam a tentativa do homem de restabelecer o lugar histórico outorgado a ele, o da razão, o da autoridade e diante da impossibilidade de reavê-lo por meio da palavra, utiliza-se da violência física como recurso para recuperar a sua posição.

Diante do menor sinal de modificação das relações de poder, tende-se a algemar a mulher ao discurso, definindo-a como fraca, frágil, desarrazoada, passiva, conduzindo-a a uma condição assujeitada. Portanto, a mulher 
não sofre apenas com a violência física, mas também com a linguagem que a submete a um ideal de feminino que se conforma a exigências de condutas, de beleza, de moda etc. ou a subjuga por meio de ameaças, gritos e humilhação do parceiro que atende a um ideal de masculinidade associado a autoridade simbólica. A violência é estabelecida e mantida na dialogicidade machista dos homens e das mulheres que produz assimetria e hierarquização na relação.

Asexualidade que é um discurso fundante e estrutura a constituição subjetiva de homens e mulheres, apresenta-se como um dispositivo que engloba as relações sociais. Portanto, faz-se presente nas vestimentas, nos artigos consumidos, nos relacionamentos amorosos e familiares, nas conversas com os amigos e não apenas na genitalização. Por isso, é relevante analisar as configurações particulares de gênero que se dão nas relações sociais entre os sexos, pois a sexualidade imprime identidade, contudo esta identidade não se encontra essencialmente em lugares prazerosos. A complexidade em abandonar o lugar da dor é retratada pela quantidade de vezes que as mulheres em situação de violência tentam se separar, mas acabam retornando ao relacionamento. A mulher confinada pelo dispositivo, imprescinde do homem para a construção de sua identidade. Portanto, homens e mulheres configuram-se entre a ordem do sujeito e a ordem coletiva, entre a subjetividade da realidade psíquica e a realidade cultural, são sujeito e objeto das relações violentas.

A essa conjuntura há que se acrescentar ainda a idolatria ao amor, uma construção cultural de longa duração que nos impõe a dependência do outro e a angústia da perda do objeto amado. Nenhum sujeito encontra-se fora desse discurso amoroso que nos constitui como sujeitos apaixonados, conjugando amor e sexualidade. Ele encontra-se naturalizado e está disseminado em diferentes linguagens como na literatura, nas novelas, nas músicas, no cinema, nas imagens etc. Esse amor superestimável se estabelece como uma obrigação e na tentativa de salvaguardá-lo há mulheres que, num imperativo inconsciente que a transcende, relacionamse com seus parceiros de forma idealizada, no plano da fantasia, ou do lugar que ela ocupou como filha na família de origem. Portanto, numa reação de defesa, a objetividade da agressão vivenciada é subjetivamente transformada em realidade psíquica com a finalidade de justificar a violência, minimizando-a e colocando-a como consequência, por exemplo, da bebida ou das drogas. Esse movimento não é uma construção individual, está acima disso, é uma praxe culturalmente construída, um aprendizado social.

A permanência da mulher em relacionamentos violentos não configura um desejo de apanhar, mas evidencia que as dinâmicas que constituem as relações sociais, consistem em relações de poder, de afeto e desejo. A força do afeto não é uma dimensão particular do sujeito, mas uma construção cultural, assim como o discurso do machismo e da sexualidade imperativa. Portanto, os serviços de assistência à mulher em situação de violência devem considerar que a violência é relacional e em decorrência disso as mulheres podem não estar dispostas a criminalizar seus parceiros ou a se separarem dele. A lógica da queixa presente nos diferentes locais que atendem às mulheres apresenta limites para acolher os paradoxos das relações de violência.

O discurso da denúncia já era presente desde a década de 80 , nos chamados SOS Mulher, os quais possuíam uma visão da mulher como categoria única, isolando o gênero de outros formadores de diferença como classe, raça, etnia, idade etc. Portanto, incorreram na armadilha do vitimismo ao impor como regra a dualidade - elas vítimas da dominação/ eles algozes dominadores, eao ignorar a dialogicidade das construções da subjetividade de homens e mulheres e das relações sociais. Contudo, não se pode negar a importante participação que tiveram no sentido de tornar pública a questão da violência contra a mulher e de configurar as agressões eram crime.

Há que se ter cuidado para não ir de um extremo ao outro, de uma visão impreterível da mulher como vítima de um sistema de dominação para uma concepção que desvitimiza para justificar a violência, imputando-lhe a culpa por provocar o ato de agressão. À mulher não se deve transferir o ônus dos relacionamentos violentos, pois ela não é produtora voluntária e nem unívoca da violência. Tanto homens quanto mulheres aderem aos discursos culturais, em suas diferentes formas de manifestação, que moldam a consciência e as ações. Os discursos são campos verbais que nos fornecem a ideia 
de mundo, são a incorporação nos corpos e nas vidas de princípios de organização do mundo social e que, embora nos pareça natural, são construídos histórica e culturalmente. Portanto, os dispositivos são constituintes da realidade social, são produtores e mantenedores de poder.

\section{REFERÊNCIAS}

ALVES, A. M. O método materialista histórico dialético: alguns apontamentos sobre a subjetividade. Revista de Psicologia da UNESP, São Paulo, v. 9, n. 1, p. 1-13, 2010. Disponível em: http://seer.assis.unesp.br/index. $\mathrm{php} / \mathrm{psicologia/article/view/422/400}$. Acesso em: 14 jan. 2018.

BARROS, A. J. da S.; LEHFELD, N. A. de S. Fundamentos de metodologia: um guia para a iniciação científica. 2. ed. São Paulo: Makron Books, 2000.

BOURDIEU, P. A dominação masculina. 2. ed. Rio de Janeiro: Bertrand Brasil Ltda, 2014.

BUTLER, J. P. Sujeitos do sexo/ gênero/ desejo: mulheres como sujeito do feminismo. In: BUTLER, J. P. Problemas de gênero: feminismo e subversão da identidade. 6. ed. Rio de Janeiro: Civilização Brasileira, 2013. p. 15-60.

CASTAÑEDA, M. O machismo invisível. Rio de Janeiro: Girafa, 2006.

CONCEIÇÃO, A. C. L. da. Teorias feministas: da "questão da mulher" ao enfoque de gênero.

Revista Brasileira de Sociologia da Emoção - RBSE, v. 8, n. 24, p. 738757, dez. 2009. Disponível em: http://paginas.cchla.ufpb.br/ rbse/Conceicao_art.pdf.Acesso em: 15 set. 2018.

INSTITUTO DE PESQUISA DATASENADO. Senado Federal. Violência doméstica e familiar contra a mulher. Brasília, 2017. 80 p. Disponível em: https://www12.senado.leg. $\mathrm{br} /$ institucional/datasenado/arquivos/aumentanumero-de-mulheres-que-declaram-ter-sofridoviolencia. Acesso em: 10 mar. 2018.

DEBERT, G. G.; GREGORI, M. F. Violência e gênero: novas propostas, velhos dilemas. Revista Brasileira de Ciências Sociais,
RBCS, v. 23, n. 66, p. 165-185, fev. 2008.

Disponível em: http://www.scielo.br/pdf/rbcsoc/ v23n66/11.pdf. Acesso em: 09 mar. 2018.

FANINI, A. M. R.; GNOATO, G.; SANTOS, M. L. dos. Cultura da violência, dispositivo do amor-paixão, sexualidade e machismo: Uma análise do discurso feminino em relacionamentos conturbados. Revista Internacional Interdisciplinar INTERthesis, Florianópolis, v. 14, n. 2, p. 132-151, maio/ ago 2017. Disponível em: https://periodicos. ufsc.br/index.php/interthesis/article/view/18071384.2017v14n2p132. Acesso em 20 fev. 2018.

FONSECA, J. J. S. da. Metodologia da pesquisa científica. Fortaleza: Universidade Estadual do Ceará, 2002. Disponível em: http:// www.ia.ufrrj.br/ppgea/conteudo/conteudo-20121/1SF/Sandra/apostilaMetodologia.pdf. Acesso em: 25 nov 2018.

FOUCAULT, M. História da sexualidade 1: a vontade de saber. 4. ed. Rio de Janeiro/ São Paulo: Paz e Terra, 2017.

GIL, A. C. Como elaborar projetos de pesquisa. 4. ed. São Paulo: Atlas, 2002.

GNOATO, G. Reflexos e reflexões sobre a escolha de um conceito de gênero em pesquisas feministas. [S.I.: s.n.], 2014. p. 1-21.

GNOATO, G. Análise do discurso feminino entre casais violentos na cultura da agressão. 2017. 252f. Tese de Doutorado (Programa de Pós-Graduação em Tecnologia e Sociedade) - Universidade Tecnológica Federal do Paraná, Curitiba, 2017. Disponível em: http:// repositorio.utfpr.edu.br/jspui/handle/1/2617.

Acesso em: jan. 2018.

GNOATO, G. O poder, o discurso, a verdade e a noção de dispositivo em Foucault. [S.I.: s.n.], 2018.

GREGORI, M. F. As desventuras do vitimismo.

Estudos Feministas, v. 1, n. 1, 1993a.

Disponível em: https://periodicos.ufsc.br/index. php/ref/article/view/15998/14498. Acesso em: 06 dez. 2018.

GREGORI, M. F. Cenas e queixas, um estudo sobre mulheres, relações violentas 
e a prática feminist. São Paulo: Paz e Terra, 1993b.

GROSSI, M. P. Vítimas ou Cúmplices? Dos diferentes caminhos da produção acadêmica sobre violência. In: Encontro Anual da APOCS, 15., 1991, Caxambu. GT 37 Relações sociais de gênero. Caxambu: [s.n.], 1991. p. 1-20. Disponível em: https://www.anpocs.com/index. php/encontros/papers/15-encontro-anual-daanpocs/gt-15/gt37-3/7127-miriamgrossi-vitimas/ file. Acesso em: 10 jul. 2018.

\section{INSTITUTO DE PESQUISA ECONÔMICA} APLICADA. Atlas da violência, Rio de Janeiro, 2018. Diponível em: http://www.ipea. gov.br/portal/images/stories/PDFs/relatorio_ institucional/180604_atlas_da_violencia_2018. pdf. Acesso em ago. 2018.

\section{IZUMINO, W. P. Justiça e violência contra} a mulher: O papel do sistema judiciário na solução dos conflitos de gênero. São Paulo: Annablume, 1998.

KRUG, E. G. et al. (eds.). Relatório Mundial Sobre Violência e Saúde, Genebra, Organização Mundial de Saúde, 2002. Disponível em: https://opas.org.br/wp-content/ uploads/2015/09/relatorio-mundial-violenciasaude.pdf. Acesso em: 03 ago. 2018.

\section{ORGANIZAÇÃO DAS NAÇÕES UNIDAS -}

ONU. Estudio a fondo sobre todas las formas de violencia contra la mujer. Informe del Secretario General. [S.I.: s.n.], 2006. p. 1-157. Disponível em: http://www.ungei.org/ N0641977_sp.pdf. Acesso em: 20 mar. 2018.

PIOVESAN, F. A Proteção Internacional dos Direitos humanos das Mulheres. Revista da Escola de Magistratura do Estado do Rio de Janeiro, Rio de Janeiro, v. 15, n. 57, p. 70-80, jan/mar 2012. Disponível em: http://www.emerj. tjrj.jus.br/revistaemerj_online/edicoes/revista57/ revista57.pdf. Acesso em: 20 abr. 2018.

PRIORE, M. D. Amores de papel. In: PRIORE, M. D. História do Amor no Brasil. 2. ed. São Paulo: Contexto, 2006. p. 225-228. Disponível em: http://files.anajatubaateniense-blogspotcom.webnode.com/200000269-43ddb44dc0/Ma ryDelPrioreHistriadoAmornoBrasil.pdf. Acesso em 20 jan. 2018.
QUATRO mulheres são assassinadas no Paraná em menos de um mês. Curitiba: Rede Paranaense de Comunicação - RPC, 02 ago. 2018. Online. Duração 1 min 44 s. Disponível em: http://g1.globo.com/pr/campos-gerais-sul/ paranatv-1edicao/videos/t/edicoes/v/quatromulheres-sao-assassinadas-no-parana-emmenos-de-um-mes/6916931/. Acesso em: 14 nov. 2018.

ROUGEMONT, D. de. O amor e o Ocidente. Tradução de Paulo Brandi, Ethel Brandi Cachapuz. Rio de Janeiro: Guanabara S.A., 1988. Disponível em: http://fernandomaues. com/noigandres/textos/lpmedieval/ ROUGEMONT, Dennis. O amor e o ocidente. pdf. Acesso em: 10 ago 2018.

SANTOS, C. M.; IZUMINO, W. P. Violência contra as mulheres e violência de gênero: Notas sobre estudos feministas no Brasil.

E.I.A.L Estudios Interdisciplinarios de América Latina y El Caribe, Tel Aviv, v. 16, n. 1, p. 147-164, 2005. Disponível em: http://www. nevusp.org/downloads/down083.pdf. Acesso em 10 mar. 2018.

SILVA, G. F. da; MACHADO JÚNIOR, S. da S. O discurso em Michel Foucault. História em reflexão, Universidade Federal de Mato Grosso, v. 8, n. 16, 2014. Disponível em: https:// www.google.com/url?sa $=t \& r c t=j \& q=\& e s r c=s \& s$ ource $=$ web\&cd $=1 \&$ ved $=2$ ahUKEwphY_ArJHfAh WHfZAKHYwaD5IQFjAAegQICRAC\&url=http\% 3A\%2F\%2Fojs.ufgd.edu.br\%2Findex.php \%2Fhi storiaemreflexao $\% 2 \mathrm{Farticle} \% 2 \mathrm{Fdownload} \% 2 \mathrm{~F} 3$ 821\%2F2086\&usg=AOvVaw2J3VaoEa0TnFtIN NSunrjs. Acesso em: 01 dez.18.

SILVEIRA, L. P. da. Serviços de atendimento a mulheres vítimas de violência. São

Paulo: Coletivo Feminista Sexualidade e Saúde, 2006. Disponível em: http://www. observatoriodeseguranca.org/files/lenirapdf.pdf. Acesso em jun. 2018.

\section{WAISELFISZ, J. J. Mapa da Violência -} Homicídio de Mulheres no Brasil. Brasília: Faculdade Latino-Americana de Ciências Sociais - FLASCO, 2015. p. 1-79. Disponível em: http://www.onumulheres.org.br/wp-content/ uploads/2016/04/MapaViolencia_2015_ mulheres.pdf. Acesso em jan.2018. 
GRECA, A. P. T.; GNOATO, G.

\section{ANÁLISIS RELACIONAL DE MUJERES EN SITUACIÓN DE VIOLENCIA}

Resumen: El objetivo de esta investigación ha sido destacar las contingencias que llevan la mujer a permanecer largos períodos en relacionamientos violentos. El estudio se caracterizó como investigación aplicada y se realizó una amplia revisión de la literatura. Se analizó la dinámica de la violencia desde una perspectiva relacional de género $y$, a través de la caracterización histórica del feminismo, se problematizó el entendimiento de la violencia como unidireccional. Se entiende que no se puede ver la violencia como una acción individual, desarticulada del contexto macro social. Los sujetos se constituyen en la configuración histórica y cultural del machismo, de la sexualidad y del amor y se comportan de acuerdo con los dispositivos discursivos que persisten en la historia del Occidente y regulan las prácticas sociales. Los procedimientos de poder rigen las relaciones entre los sujetos y condicionan el cumplimiento de lo que dice el discurso. Por lo tanto, las relaciones de poder se establecen a través de discursos y un gran contingente de correlaciones de poder se encuentra en el campo de las relaciones entre hombres y mujeres.

PALABRAS CLAVE: Violencia; Perspectiva relacional de género; Dispositivos; Discursos. 